\title{
Rape and Medical Consequences among Girls and Women Victims during the Post-Armed Conflict Context in Congo
}

\author{
Ndziessi Gilbert ${ }^{*}{ }^{\circledR}$, Bintsene-Mpika Gickelle², Aloumba Julius Axel33, Bileckot Richard4 \\ ${ }^{1}$ Faculty of Health Sciences, Department of Public Health, Marien Ngouabi University, Brazzaville, Congo \\ ${ }^{2}$ Department of Gynaecology and Obstetrics, Brazzaville University Hospital, Brazzaville, Congo \\ ${ }^{3}$ Infectious Diseases Services, Brazzaville University Hospital, Brazzaville, Congo \\ ${ }^{4}$ Department of Medicine, Faculty of Health Sciences, Marien Ngouabi University, Brazzaville, Congo \\ Email: ^ndziessi@yahoo.fr
}

How to cite this paper: Gilbert, N., Gickelle, B.-M., Axel, A.J. and Richard, B. (2019) Rape and Medical Consequences among Girls and Women Victims during the Post-Armed Conflict Context in Congo e. Open Journal of Epidemiology, 9, 75-81. https://doi.org/10.4236/ojepi.2019.91007

Received: December 31, 2018

Accepted: February 17, 2019

Published: February 20, 2019

Copyright $\odot 2019$ by author(s) and Scientific Research Publishing Inc. This work is licensed under the Creative Commons Attribution International License (CC BY 4.0).

http://creativecommons.org/licenses/by/4.0/

\begin{abstract}
Rape is a criminal, aggressive and violent act to have sexual intercourse with a person without her consent. Few studies have been conducted on rape and sexual assaults related to armed conflict in developing countries. The objective of this study was to assess the magnitude of rape and its medical consequences among victims during armed post-conflict period in Brazzaville from January to December 1999. Rape victim was defined as woman or girl having received medical care from January to December 1999 in care units following reporting having incident of rape. SPSS V 20 software was used for the analyses. A total of 1282 victims were assessed. We documented 106 post-rape pregnancies, of which 58 (54.7\%) ended in abortion, 15 (14.2\%) in miscarriage and $33(31.1 \%)$ in childbirth. Sexually transmitted infections (STIs) were common, with 560 (44\%) cases among the 1282 victims. Of these, 301 (23\%) had trichomoniasis, 123 (10\%) had salpingitis, 89 (7\%) had vaginal candidiasis and 38 (3\%) had gonorrhea. A large proportion of morbidity 362 (28\%) was attributed to vulvovaginal injuries and traumatic pelvic pains. In conclusion, our study highlights that rape practice was common in context of armed conflict in Congo. Medical consequences were unwanted pregnancies leading to unsafe abortions, STIs and physical injuries. Results argue in favor of effective public health interventions for a better prevention and care of victims during and after armed conflict.
\end{abstract}

\section{Keywords}

Rape, Armed Conflict, Congo 


\section{Introduction}

Sexual assaults, particularly against women, include the various forms that the most common is the rape [1]. In this study, it is defined as a criminal, aggressive and violent act or a person forcing another to have sexual intercourse without her consent [2]. Available data have showed that perpetrators of sexual assaults are often driven by a desire of power and domination [1] [2]. Thus, during armed conflicts, there is an increased risk of sexual violence, of which sexual assault seems to be the most common form [3]. Due to the sensitivity of the subject, sexual assaults and its consequences are almost universally under-reported [4]. This is especially common in developing countries where violence against women does not integrate any data collection system and where armed conflicts are frequent. The objective of this retrospective study was to assess the magnitude of sexual assaults and its medical consequences among victims during the post-conflict period in Republic of Congo from January to December 1999, based on data collected in four (4) care units in Brazzaville, with a focus on collecting epidemiological data for public health interventions.

\section{Material and Methods}

\subsection{Study Design}

This is a retrospective, descriptive, cross-sectional study of 1282 victims of rape recorded between January and October 1999, in post-war context in Brazzaville. This period was characterized by the massive return to Brazzaville of people who were forced to move out because of the fighting between the belligerents during the 1998 armed conflict which was started in June of this year. Data were collected in four (4) care units (CU) for victims of gender-based violence: Talangai District Hospital in the northern Brazzaville area, Makéléléké District Hospital in the southern Brazzaville erea and two (2) health centres i.e. Indzouli in the arrondissement of Mfilou and Plateau de 15 ans in the arrondissement of Moungali. In all CU, medical assistance for victims included: consultation by medical teams, screening and treatment sexually transmitted infections (STIs) using a syndromic approach (no para-clinical examination was performed), unwanted pregnancies prevention with emergency contraceptive pill PC4 for victims who were received within 72 hours post-rape and who were not pregnant. Clinical diagnosis of pregnancy was confirmed using urinary test of chorionic gonadotropin hormone (CGH). All pregnant women have received a birth Kit. All victims have received psychological assistance provided by clinician psychologists.

From medical observations, data including marital status, level of education and clinical information were collected. Indeed, a household survey was conducted in the 8th month after the first visit to the care unit to assess the status of pregnancies post sexual assault, using a pre-test questionnaire administered face-to-face by trained social workers. All pregnancies recorded between January and October 1999 was expected to end during the household 
survey period. Questionnaire allowed having information on the outcome of each pregnancy (childbirth, abortion or miscarriage). Rape is a criminal, aggressive and violent act to have sexual intercourse with a person without her consent. Rape victim was defined as woman or girl having received medical care from January to December 1999 in care units following reporting having incident of rape. Only cases of rape that occurred after 5 June 1998 (i.e. beginning of the armed conflict) were included in the analyses. Cases of rape occurred prior to this date have been excluded. Data on women and girls not involved in sexual assault and attended CU for others motifs of consultations during the study period were also excluded for analyses. The study protocol was approved by the national departmental committee of ethics in biomedical research. Data were collected and analyzed anonymously.

\subsection{Variables Used for Analyses}

Variables used for analyses were classified into the two following categories:

- Socio demographic characteristics including age (years), matrimonial status (not in union, in union, widowed or divorced) and education level (not all education, primary, college or grammar school, university).

- Access to care: only one variable was analysed in terms of the delay (days) from incident of rape to seeking care.

- Rape medical consequences including transmissible sexual infections (trichomonas, salpingitis, vaginal candidiasis, gonorrhea), vulvovaginal injuries, traumatic pelvic pain and post-rape pregnancies.

\subsection{Statistical Analyses}

Descriptive statistics were used to describe study population characteristics. Frequencies were calculated for each socio-demographic variable. Medical consequences of sexual assaults on victims were reported in a table with and their frequencies were calculated. Data were recorded and analyzed using SPSS V 20 software.

\section{Results}

\subsection{Main Characteristics of Victims}

A total of 1282 victims of rape were enrolled in this study. Median age was 24 years. Minimum age was 8 and maximum 65 years. As shown in Table 1, majority of sexual assault victims (60\%) were in the age range of 15 - 24 years, while age groups of $24-45$ and over 45 years had $26.0 \%$ and $4.7 \%$ victims, respectively. Children and teens aged 8 to 15 represented $9.4 \%$ of sexual assault victims. Regarding education, more than 6 out of 10 victims $(67.2 \%)$ had a secondary school level, 210 (16.4\%) a elementary level, $22(1.7 \%)$ a university level and 188 (14.7\%) not attending school. Regarding marital status, among 1162 victims who were aged over 14 years, 711 (61.2\%) were not in union, 300 (25.8\%) in union and $151(13.0 \%)$ widowed or divorced. The remaining 120 
(9.4\%) victims were children and teens aged 8 to 15 . Delay in seeking care was within 3 days after sexual assault act for 105 (8.2\%) victims and over 3 days for remaining victims. Means delay in seeking care was 185 days.

\subsection{Medical Consequences of Rape}

Details for medical consequences of sexual assault in victims are provided in Table 2. A total of 1282 survivors of rape records were assessed. Sexually transmitted infections were common among victims, 560 (44\%) cases among the 1282 victims. Of these, 301 (23\%) had trichomonas infection, 123 (10\%) had acute salpingitis, $89(7 \%)$ had vaginal candidiasis and $38(3 \%)$ had gonorrhoea. A significant proportion of morbidity 362 (28\%) was attributed to vulvovaginal lesions and traumatic pelvic pain. We have documented 106 pregnancies that were reported as a result of rape, of which 58 (54.7\%) ended in abortion, 15 $(14.2 \%)$ in miscarriage and $33(31.1 \%)$ in childbirth (see Figure 1 ).
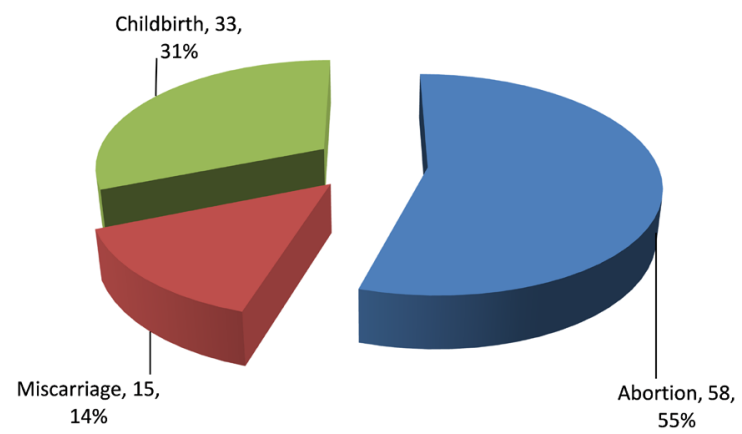

Figure 1. Outcome of post-rape pregnancies among girls and women victims attended care units in post-armed conflict in Brazzaville, January-December $1999(\mathrm{~N}=106)$.

Table 1. Main socio-demographic of victims of rape attended care units in post-armed conflict in Brazzaville, January-December 1999 ( $\mathrm{N}=1282)$.

\begin{tabular}{lccc}
\hline & Socio-demographic characteristics & $\mathrm{n}$ & $\%$ \\
\hline Age (years) & & & \\
& $8-14$ & 120 & 9.4 \\
$15-24$ & 769 & 60 \\
$25-45$ & 333 & 26 \\
& $46-65$ & 60 & 4.7 \\
Total & 1282 & 100 \\
Education level & & \\
& Not all education & 188 & 14.7 \\
& Primary & 213 & 16.6 \\
& College/Grammar school & 859 & 67 \\
& University & 22 & 1.7 \\
Total & 1282 & 100 \\
Matrimonial status (For person aged over 14 years (n=1162)) & & \\
& Not in union & 711 & 61.2 \\
& in union & 300 & 25.8 \\
& Widowed or divorced & 151 & 13.0 \\
Total & 1162 & 100.0 \\
\hline
\end{tabular}


Table 2. Distribution of medical consequences of rape among girls and women victims attended care units in post-armed conflict in Brazzaville, January-December 1999 (N = 1282).

\begin{tabular}{|c|c|c|c|}
\hline Major clinical signs & Diagnosis & $\mathrm{n}$ & $\%$ \\
\hline Not having a clinical signs & & 253 & 20 \\
\hline Heavy vaginal discharge, lactic appearance with bulls & Trichomoniasis & 301 & 23 \\
\hline yellow vaginal discharge & Gonorrhea & 38 & 3 \\
\hline Pasty vaginal discharge \pm vulvovaginal pruritus & Vaginal candidiasis & 89 & 7 \\
\hline $\begin{array}{l}\text { having adnexa or cervix pains when touching } \\
\text { them }+ \text { temperature } \geq 38^{\circ} \mathrm{C}+\text { vaginal discharge }\end{array}$ & Salpingitis & 123 & 10 \\
\hline Vulvo-vaginal ecchymosis and/or tears & Traumatic lesion & 30 & 2 \\
\hline Pelvic pains & Pelvic inflammatory disease & 332 & 26 \\
\hline $\begin{array}{l}\text { Absence of menstruation, } \\
\pm \text { closed cervix }+ \text { increase in uterus volume }{ }^{*}\end{array}$ & Gravidic amenorrhea & 116 & 9 \\
\hline Total & & 1282 & 100 \\
\hline
\end{tabular}

*Syndromic diagnosis confirmed by a urine test.

\section{Discussion}

In this study, we assessed medical consequences of rape in post-conflict context in Congo. Data used for this study may be seemed old, collected 9 years ago in a post-armed conflict context. However, it is well known that war contexts are complex, which explains why this study wasn't published for 9 years. Despite this delay, our publication is draw to highlight the consequences of armed conflict on our families, including the fact that many girls and women have lives shattered by sexual violence exacerbated by the effects of war. In addition, this study is the first study able to provide such in-depth information on sexual violence and its medical implications during the turbulent period of 1995 and 1998, when Republic of Congo had experienced repeated armed conflicts.

The large number of 1282 rape victims registered in care units over a period of one year corroborates the opinion that sexual aggressions has increased as a result of armed conflicts [3]. This situation reflects the dysfunction of individual protection institutions, including those for the protection of children such as the family commonly observed during wars. The results of our study show that any woman of any age, marital status and education level can be a victim of rape. However, data on the perpetrators of the rapes could not be collected. Indeed, during armed conflicts, it is difficult to identify the perpetrators.

Victims of rape are at high risk of contracting a sexually transmitted infection (STI). Indeed, these are unprotected sexual penetrations, so perpetrators with an STI can transmit it to their victims. There have been no previous studies on the frequency of STIs among rape victims in the Congolese context. Our results show that more than 4 out of 10 victims suffered from an STI, trichomonas infection and salpingitis were the most frequent STIs [5] [6] [7]. However, it is difficult to determine whether these infections preceded the act of rape. 
High risk of pregnancy following sexual assault has been documented in several studies [8] [9]. However, none of these studies have elucidated the prevalence of such pregnancies among rape victims in the context of armed conflict. In this study, 9 rapes out of 100 rape cases, among victims in childbearing years, led to pregnancies. This suggests that medical assistance programs target the victims of rape should include in their activities a package-care of pregnant women and births. The literature shows that abortion is very common among women with unwanted pregnancies [8] [9]. Or, pregnancies related to sexual assault are by definition unwanted pregnancies. Our results do not corroborate those obtained in studies in the USA that had obtained an abortion frequency of $1.9 \%$ to 5\% [10] [11] among post-rape pregnant women. Rather, our results reveal that one in two pregnancies resulting from rape (50\%) ends in an abortion. The difference between these results can be explained by the fact that the studies were conducted in two different contexts. This study analyses the data collected in an immediate post-conflict context.

The following limitations should be considered in interpreting the results of this study. First, all results from this study are based on data from four (4) care units (CU) for victims of sexual violence in Brazzaville. Therefore, the findings of this study may not be generalizable to others victims of rape who choose not to use these services following sexual assault. Second, the study is limited by the fact that STIs were assessed using exclusively clinical. It is well known that non-use of para-clinical tests can lead to misdiagnosis of STIs. However, in this study, to minimize this biais, the syndromic approach was used exclusively by physicians experienced in the management of STIs. Third, the definition of rape victim in this study was strictly based on victim statements. It could certainly have been interesting to match these victim declarations with police and legal service data. But, as previously mentioned, during contexts of armed or post-armed conflict, these services are generally not operational and even if they are available, people don't trust to them.

\section{Conclusion}

Our study highlights that rape practice was common in context of armed conflict in Congo. Medical consequences were unwanted pregnancies with their corollaries clandestine abortions, STIs and physical injuries. Results argue in favor of effective public health interventions for a better prevention and care of victims during and after armed conflict.

\section{Acknowledgements}

The authors want to pay tribute to the women victims of rape who have had the courage to seek care. In fact, their massive attendance has made it possible to write this paper as an advocacy tool. Authors wish also to thank medical and psychosocial teams of care units for their involvement in reconstruction of 
women who have been sexually abused.

\section{Conflicts of Interest}

The authors declare no conflicts of interest regarding the publication of this paper.

\section{Authors' Contributions}

NG contributed to the development of the study protocol, data collection in the PEC units, production of the database, statistical analysis of the data, literature review and drafting of the first draft of the paper. GBM, AJA, BR and NG contributed to the revision of the article. All authors approved the final version of the article.

\section{References}

[1] OMS (2002) Rapport mondiale sur la violence et la santé. http://www.who.int/violence_injury_prevention/violence/world_report/fr/full_fr.pdf

[2] WHO (2005) Etude multipays de l'OMS sur la santé des femmes et la violence domestique à l'égard des femmes: Premiers résultats concernant la prévalence, les effets sur le plan sanitaire et les réactions des femmes: Rapport succint. http://apps.who.int/iris/handle/10665/43366\#sthash.kkheDb6i.dpuf

[3] Josse, E. (2007) Violences sexuelles et conflits armés en Afrique. http://www.resilience-psy.com/IMG/pdf/violences_sexuelles_conflit_afrique.pdf

[4] Watts, C. and Zimmerman, C. (2002) Violence against Women: Global Scope and Magnitude. Lancet, 359, 1232-1237. https://doi.org/10.1016/S0140-6736(02)08221-1

[5] Jo, S., et al. (2011) Prevalence and Correlated Factors of Sexually Transmitted Diseases-Chlamydia, Neisseria, Cytomegalovirus-In Female Rape Victims. The Journal of Sexual Medicine. 8, 2317-2326. https://doi.org/10.1111/j.1743-6109.2010.02069.x

[6] Jenny, C., et al. (1990) Sexually Transmitted Diseases in Victims of Rape. New England Journal of Medicine, 322, 713-716. https://doi.org/10.1056/NEJM199003153221101

[7] Schwarcz, S.K. and Whittington, W.L. (1990) Sexual Assault and Sexually Transmitted Diseases: Detection and Management in Adults and Children. Reviews of Infectious Diseases, 12, S682-S690. https://doi.org/10.1093/clinids/12.Supplement_6.S682

[8] Ekanem, E.I., et al. (2009) Clinical Presentation and Complications in Patients with Unsafe Abortions in University of Calabar Teaching Hospital, Calabar, Nigeria. Nigerian Journal of Medicine, 18, 370-374.

[9] Cleland, J. and Ali, M.M. (2004) Reproductive Consequences of Contraceptive Failure in 19 Developing Countries. Obstetrics \& Gynecology, 104, 314-320. https://doi.org/10.1097/01.AOG.0000134789.73663.fd

[10] Perry, R., et al. (2015) Prevalence of Rape-Related Pregnancy as an Indication for Abortion at Two Urban Family Planning Clinics. Contraception, 91, 393-397. https://doi.org/10.1016/j.contraception.2015.01.012

[11] Holmes, M.M., et al. (1996) Rape-Related Pregnancy: Estimates and Descriptive Characteristics from a National Sample of Women. American Journal of Obstetrics and Gynecology, 175, 320-324; Discussion 324-325. https://doi.org/10.1016/S0002-9378(96)70141-2 